\title{
ENSINO POR INVESTIGAÇÃO EM UMA PERSPECTIVA INTEGRADA: UMA ABORDAGEM PARA OS PROJETOS INTEGRADORES
}

\author{
Leonardo Emmanuel Fernandes de Carvalho; Emanuel Neto Alves de Oliveira; Ayla Marcia \\ Cordeiro Bizerra \\ Instituto Federal de Educação, Ciência e Tecnologia do Rio Grande do Norte \\ DOI: 10.15628/rbept.2018.7251
}

Artigo submetido em abr/2018 e aceito em ago/2018

\begin{abstract}
RESUMO
O Ensino de Ciências, apesar de ter relevante importância para a formação educacional do estudante, encontra resistência e dificuldade de aprendizagem devido à algumas práticas que se apresentam fragmentadas, predominantemente conceituais e descontextualizadas. $O$ Ensino Médio Integrado, no entanto, permite estratégias metodológicas que visam superar essas barreiras, buscando a resolução de problemas e promovendo práticas interdisciplinares. O trabalho apresentado tem como objetivo discutir a abordagem do Ensino de Ciências por Investigação como uma possibilidade de desenho dos projetos integradores para o Instituto Federal de Educação, Ciência e Tecnologia do Rio Grande do Norte (IFRN). O estudo se baseia em uma revisão bibliográfica sobre o Ensino de Ciências por Investigação e a análise nos documentos educacionais norteadores do IFRN, tais como o Projeto Político Pedagógico (PPP) e a Organização Didática, em que se estabelecem os princípios assumidos para a proposição e elaboração de estratégias que visem à integração curricular no referido instituto. Tal relação permite repensar em estratégias que valorizem o ensino em conjunto com a pesquisa científica como um princípio pedagógico e o trabalho como um princípio educativo, corroborando para promover uma educação científica crítica que auxilie os estudantes em sua formação cidadã e para o mercado de trabalho.
\end{abstract}

Palavras-Chave: Ensino Médio Integrado Integrada, Ensino de Ciências, Interdisciplinar, Institutos Federais de Educação, Ciência e Tecnologia.

\section{INQUIRY TEACHING IN AN INTEGRATED PERSPECTIVE: AN APPROACH TO IFRN INTEGRATING PROJECTSABSTRACT}

Science Education, although of relevant importance for the educational formation of the student, finds resistance and learning difficulty due to some practices that are fragmented, predominantly conceptual and decontextualized. Integrated High School, however, allows methodological strategies to overcome these barriers, seeking to solve problems and promoting interdisciplinary practices. The purpose of this work is to discuss the Inquiry Science Teaching approach as a possibility of designing the integrative projects of Federal Institute of Education, Science and Technology of the Rio Grande do Norte (IFRN). The study is based on a literature review on Inquiry Science Teaching and analysis in the IFRN guiding educational documents, such as the Pedagogical Political Project (PPP) and Didactic Guidance, in which the principles established for proposing and elaborating strategies for curricular integration. This relationship allows us to rethink strategies that value teaching associated with scientific research as a pedagogical principle and work as an educational principle, corroborating to promote a critical scientific education that assists students in their formation for citizenship and for work market.

Keywords: Integration High School, Science Education, Interdisciplinarity, Federal Institutes. 


\section{INTRODUÇÃO}

O Ensino de Ciências apresenta-se como um campo de estudos e pesquisas de grande discussão e relevância por parte dos educadores científicos, contribuindo na formação de professores que irão atuar nas diversas disciplinas científicas (MARANDINO, 2003; MARTINS, 2005; CACHAPUZ, GIL-PÉREZ, CARVALHO e VILCHES, 2011; DELIZOICOV, ANGOTTI E PERNAMBUCO, 2011).

Apesar do Brasil ser bastante produtivo em suas pesquisas científicas nessa área, em nível nacional e internacional, as discussões se restringem às academias e pouco contribuem para mudanças nas realidades escolares, principalmente no que diz respeito à incorporação de novas metodologias e concepções de aprendizagem em ciências (MARANDINO, 2003; NARDI e ALMEIDA, 2007).

É cada vez mais consenso entre os teóricos da educação de que é preciso haver uma reformulação nos conteúdos, métodos e na forma como o conhecimento científico é transmitido nas escolas. Discussões vêm sendo feitas ao longo dos anos sobre métodos mais efetivos de se ensinar ciências aos estudantes, considerando aspectos relevantes na atualidade, como a abordagem da relação entre Ciência, Tecnologia e Sociedade (CTS) e que se mostrem significativos ao aprendizado (AMORIM, 2001; BORGES e LIMA, 2007; CARLETTO e PINHEIRO, 2010; GOUW, MOTA e BIZZO, 2013).

Neste artigo, a discussão é feita sobre duas problemáticas que se apresentam no Ensino de Ciências na atualidade: a didática empreendida na transmissão do conhecimento científico e a sua organização curricular fragmentada. A primeira delas é colocada diante de uma didática enciclopédica e reprodutivista que não se preocupa com aspectos críticos do conhecimento, o mundo das experiências dos sujeitos aprendentes, mas se considera apenas a sua dimensão conceitual (CARVALHO, 2004; CARLETTO e PINHEIRO, 2010). Enquanto que a segunda é decorrente de uma visão fragmentada dos conhecimentos científicos que não prepara 0 estudante para se deparar com problemas reais e adotar uma visão mais complexa da totalidade, havendo a necessidade de recorrer a um corpo de conhecimentos das diversas ciências, bem como propor ações inter e transdisciplinares para mitigar esses problemas (MORIN, 2011; FAZENDA, 2015).

Uma das possibilidades para o Ensino de Ciências se tornar mais significativo e atrativo para os estudantes é utilizar as chamadas metodologias ativas, que são aquelas que estimulam a autonomia estudantil, permitindo que os mesmos problematizem situações cotidianas e busquem soluções inteligentes e criativas (SOBRAL e CAMPOS, 2012). Estas metodologias se baseiam nos fundamentos científicos, bem como em teorias 
e princípios que foram incorporados ao longo de sua vida escolar, tais como metodologia de projetos, abordagens temáticas, Aprendizagem Baseada em Problemas (ABP), entre outras (MORÁN, 2015).

Uma dessas abordagens que apontam para um maior dinamismo e participação estudantil é o Ensino de Ciências por investigação. Através desta abordagem didática, o estudante é levado a perceber as incoerências e complexidades da natureza da ciência, bem como assumir posturas críticas e éticas diante do conhecimento científico produzido e assimilado, levando-o a ser partícipe fundamental do processo de aprendizagem (AZEVEDO, 2004; MUNFORD e LIMA, 2007).

Com relação à problemática da fragmentação do conhecimento, é possível superá-la a partir de perspectivas integradas e interdisciplinares de educação, como pressupõe o Ensino Médio Integrado. Este projeto proposto para a Educação Profissional, não se resume apenas a uma formação voltada para o mercado de trabalho, para atender às exigências demandadas pelo capital (ARAUJO e FRIGOTTO, 2015). Em oposição à isso, o projeto é pensado como uma travessia para um projeto futuro de sociedade, que não se materializa devido às condicionantes históricas que o impossibilitam (FRIGOTTO, CIAVATTA E RAMOS, 2005).

Para Ramos (2014), a integração pode assumir diversos sentidos no processo de formação dos estudantes e das práticas educativas dos professores: o sentido filosófico, quando estabelece como conceito central o trabalho como práxis social e pedagógica, permeando múltiplas dimensões formativas do sujeito (a ciência, a tecnologia e a cultura); o sentido ético e político, quando determina que uma formação profissional é indissociável de uma formação básica e é direito e necessidade para os estudantes do ensino médio; e o sentido epistemológico que revela a totalidade do conhecimento, permitindo perceber que as disciplinas científicas agem como mediações para a compreensão da realidade e que apresentam possibilidades de visões múltiplas e complexas.

Assim, é adotado nos Institutos Federais de Educação, Ciência e Tecnologia (IFs) o currículo integrado, baseando-se nessas perspectivas da interdisciplinaridade e da integração como princípios, bem como de uma formação omnilateral que permeie aspectos científicos, culturais, tecnológicos e profissionais (PACHECO, 2010). Este é estruturado por conhecimentos de formação geral (eixo estruturante), representados pelas disciplinas formais do Ensino Médio nos cursos técnicos integrados, bem como conhecimentos específicos da formação técnica (eixo tecnológico) que permitem espaços interessantes para se estabelecer propostas integradoras, bem como instrumentos metodológicos como o projeto integrador (SOUZA, SILVA e SILVA, 2017).

O objetivo deste trabalho, portanto, é discutir a abordagem do Ensino de Ciências por Investigação como uma possibilidade de desenho dos 
projetos integradores nos cursos técnicos integrados do Instituto Federal do Rio Grande do Norte (IFRN).

\title{
2 POR QUE PROPOR O ENSINO POR INVESTIGAÇÃO? UMA BUSCA POR UMA EDUCAÇÃO CIENTÍFICA
}

A educação científica é um movimento que desde a década de 60 vem sendo proposto por parte dos teóricos na Didática da Ciência, mas que encontra forte respaldo nos dias atuais, uma vez que se vivencia certa crise nos modelos educacionais científicos (SASSERON, 2011). Este movimento de educação científica procura democratizar o acesso da ciência para todos os cidadãos, considerando a inserção desse conhecimento como um componente essencial na formação do indivíduo e na sua participação nas esferas sociais.

Segundo a Conferência Mundial sobre a Ciência para o século XXI, realizada em Budapeste em 1999:

\begin{abstract}
Para que um país esteja em condições de satisfazer as necessidades fundamentadas de sua população, o ensino das ciências e a tecnologia é um imperativo estratégico. Como parte dessa educação científica e tecnológica, os estudantes deveriam aprender a resolver problemas concretos e a satisfazer as necessidades da sociedade, utilizando as suas competências e conhecimentos científicos e tecnológicos. (CACHAPUZ, GILPÉREZ, CARVALHO E VILCHES, 2011 apud Conferência Mundial sobre a Ciência, 1999, p.18)
\end{abstract}

O movimento da educação científica surge para superar a visão da ciência como algo abstrato, de difícil compreensão e inacessível à maior parte da população. Tenta também desmistificar os estereótipos dos cientistas, bem como os critérios rígidos do método científico (PAVÃO e FREITAS, 2011; DELIZOICOV, ANGOTTI e PERNAMBUCO, 2011). É preciso atentar que um movimento de educação científica permite o estudante estender 0 seu conhecimento para além do conceitual, entendendo que a ciência é uma construção social progressiva, que está sujeita à periódicas modificações, bem como ela não está isenta de valores e posicionamentos ideológicos que exigem do cientista uma postura ética na sua prática (CARVALHO, 2004).

Não se trata de preparar os nossos estudantes para serem cientistas, mas de dialogarem com os fatos e descobertas científicas e tecnológicas. Se os estudantes têm que assumir uma postura de cidadãos responsáveis, é preciso que sejam proporcionadas oportunidades para analisar os problemas globais que caracterizam essa situação de emergência planetária e considerar as possíveis soluções (CACHAPUZ, GIL-PÉREZ, CARVALHO E VILCHES, 2011). 
Diante disso, as novas metodologias educacionais têm evidenciado que os estudantes desenvolvem melhor a sua compreensão conceitual e aprendem mais sobre a natureza da ciência quando participam de investigações científicas, em que permitem oportunidade para se estabelecer a reflexão sobre o processo envolvido (AZEVEDO, 2004).

O Ensino de Ciências por Investigação constitui-se em uma
abordagem
aproximar os conhecimentos científicos dos conhecimentos escolares, mobilizando a atividade do aprendiz ao invés de sua passividade.

De acordo com Vieira (2012)

\begin{abstract}
Entende-se o ensino por investigação como uma abordagem de ensino que reproduz parcialmente a atividade científica, permitindo que os alunos questionem, pesquisem e resolvam problemas, levantando hipóteses e investigando até chegarem a explicação desses fenômenos. (VIEIRA, 2012, p. 2).
\end{abstract}

A investigação em sala de aula deve oferecer condições para que os estudantes possam resolver problemas, analisem relações causais entre 0 que se observa e os fenômenos naturais, utilizando-se de raciocínio lógico, hipotético-dedutivo, bem como possibilitar uma mudança conceitual em concepções previamente estabelecidas (SASSERON, 2015).

Para Sasseron (2015)

\begin{abstract}
Como abordagem didática, o ensino por investigação demanda que o professor coloque em prática habilidades que ajudem os estudantes a resolver problemas a eles apresentados, devendo interagir com seus colegas, com os materiais à disposição, com os conhecimentos já sistematizados e existentes. Ao mesmo tempo, o ensino por investigação exige que o professor valorize pequenas ações do trabalho e compreenda a importância de colocá-las em destaque como, por exemplo, os pequenos erros e/ou imprecisões manifestados pelos estudantes, as hipóteses originadas em conhecimentos anteriores e na experiência de sua turma, as relações em desenvolvimento. É um trabalho em parceria entre professor e estudantes. (SASSERON, 2015, p. 58).
\end{abstract}

Caracteriza-se, portanto, em uma forma de trabalho utilizada pelo professor para fazer com que a turma se engaje de forma ativa na construção do fazer científico. Ao expor situações reais e levantar problemáticas, os estudantes se deparam com uma ciência viva em que são necessários processos de investigação e postura crítica para a realização de experimentos, análise de resultados e argumentação de ideias (AZEVEDO, 2004). Dessa forma, o ensino por investigação está em consonância com as 
propostas levantadas por uma educação científica mais democrática, prática e crítica.

\section{ENSINO POR INVESTIGAÇÃO NO MUNDO E NO BRASIL: ANTECEDENTES HISTÓRICOS}

No início do século XX, alguns filósofos e educadores contestavam o modelo vigente de educação em que os conhecimentos eram transmitidos como prontos e acabados, uma concepção herdada das correntes do indutivismo e do positivismo. John Dewey (1859-1952), um filósofo americano, aparece como uma das figuras que critica o ensino de ciências, que para ele só enfatizava o acúmulo de informações acabadas, sem levar o estudante a entender a ciência como um método que ajuda a transformar formas de pensamento, defendendo que a ciência é mais que um corpo de conhecimentos a ser aprendido e que sofre influência das relações entre ciência e sociedade (VIEIRA, 2012).

Ele queria reconstruir a concepção do conhecimento vigente integrando-o aos objetos da ciência, chamando essa integração de experiência. Dessa forma, o que é importante para a vida humana, é importante para a ciência (RODRIGUES e BORGES, 2008).

Para Dewey, o método científico seria um modelo eficaz para utilizar as experiências dos estudantes, fazendo valer as etapas de: definição do problema, sugestão de uma solução, desenvolvimento e aplicação do teste experimental e formulação de conclusão. Apesar destas proposições inovadoras, as ideias de Dewey não foram implementadas no modelo educacional norte americano, principalmente porque este era opositor ao modelo de desenvolvimento capitalista (VIEIRA, 2012; VALDEZ, 2017).

Um outro nome que surge nessa tendência é o filósofo e biólogo Joseph Schwab (1909-1988). O mesmo afirmava que a ciência era constituída tanto por estruturas conceituais, quanto por procedimentos que foram construídos e revisados ao longo da história. Por isso, o ensino e a aprendizagem em ciências deveriam refletir esse modo de compreender os conhecimentos científicos (MUNFORD e LIMA, 2007).

Para Schwab, o aluno deveria compreender esse papel dinâmico da ciência e perceber que a mesma é um empreendimento coletivo. Neste passo, o professor tem papel fundamental para fornecer exemplos de atividade investigativa e que esta seja norteadora para que os alunos se apropriem dos temas e princípios científicos (VIEIRA, 2012).

O pioneirismo das mudanças em Ensino de Ciências foi alcançado sobretudo nos Estados Unidos e na Europa. O Project 2061 - Science For All Americans (AAAS, 1989) foi um movimento de alfabetização científica que ocorreu nas escolas americanas que recomendava que o ensino de ciências deveria ser consistente com a natureza da investigação científica e que os 
estudantes deveriam estar a par de princípios, procedimentos, aparelhos tecnológicos, a construção histórica da ciência, bem como assumirem posturas críticas sobre o empreendimento científico (ZOMPERO e LABURÚ, 2011).

Entre as recomendações propostas nesse documento, o Ensino de Ciências deve ser pautado nos seguintes aspectos:

- Discussões sobre a natureza da ciência nas investigações realizadas em sala de aula;

- Relações das atividades de ensino de ciências por investigação com aspectos sociais, dando ao movimento Ciência, Tecnologia e Sociedade (CTS).

No Brasil, as reformas curriculares ocorridas na década de 50 e 60 tiveram o papel de trazer a investigação científica para o ensino de ciências, principalmente com a criação do Instituto Brasileiro de Educação, Ciência e Cultura (IBECC), que produziam materiais didáticos voltados para uma aprendizagem da ciência como uma atividade investigativa. No entanto, a maioria das atividades propostas se baseavam em processos investigativos rígidos, não incorporando uma visão científica dos sujeitos, dos valores e posicionamentos (MUNFORD e LIMA, 2007; ANDRADE, 2011).

Algumas iniciativas que integram o ensino por investigação com as práticas pedagógicas começaram a circular no Brasil no final da década de 70 com a formação do Laboratório de Pesquisa e Ensino de Física da Faculdade de Educação da Universidade de São Paulo. A partir daí, surge em 2001 o Projeto $A B C$ da Educação Científica - Mão na massa, e em 2005 a criação do curso de Especialização em Ensino de Ciências por Investigação pelo Centro de Ensino de Ciências e Matemática de Minas Gerais (CECIMIG), da Faculdade de Educação da Universidade Federal de Minas Gerais (VIEIRA, 2012).

\section{O PROJETO INTEGRADOR NOS DOCUMENTOS OFICIAIS DO IFRN: PROJETO POLÍTICO PEDAGÓGICO (PPP) E ORGANIZAÇÃO DIDÁTICA (OD)}

Após uma breve caracterização da abordagem do Ensino de Ciências por Investigação, passamos a caracterizar os documentos oficiais que nortearam nossa pesquisa sobre os projetos integradores, o Projeto Político Pedagógico (PPP) e a Organização Didática (OD) do IFRN.

O PPP do IFRN corresponde ao documento de construção coletiva que reflete a gestão democrática existente nos processos educativos. "Sistematiza concepções, princípios e diretrizes norteadoras das práticas e das políticas educativas em âmbito local" (IFRN, 2012). Representa uma identidade cultural da instituição, sendo um produto do momento histórico vivenciado. 
Os projetos integradores estão contemplados na sessão referente às Diretrizes para a prática pedagógica, onde são apresentadas as concepções, os objetivos e as metodologias dos projetos integradores. Desse modo, o IFRN concebe os projetos integradores como:

[...] estratégia metodológica articulada à inovação da prática, à melhoria da ação pedagógica e à ressignificação do processo de ensino e aprendizagem. Essa metodologia visa extrapolar os limites e a burocratização técnica da elaboração de projetos e passa a se constituir, qualitativamente, em processos de investigação da realidade e em processos de idealização de situações de aprendizagens mais significativas. Para tanto, os projetos integradores sustentam-se na interdisciplinaridade, na contextualização de saberes, na cientificidade e na interrelação entre teoria e prática. (IFRN, 2012, p.78).

A resolução $n^{\circ}$ 38/2012 do Conselho Superior do Instituto Federal de Educação, Ciência e Tecnologia do Rio Grande do Norte (CONSUP-IFRN) determinou que o volume III do Projeto Político Pedagógico seja direcionado à normatização da Organização Didática do IFRN. A Organização didática, por sua vez, constitui um documento que "apresenta as normas didáticopedagógicas para a organização geral do ensino e para o planejamento e funcionamento de todas as ofertas educacionais do IFRN" (CONSUP-IFRN, 2012).

Os projetos integradores são contemplados na seção I, do capítulo XII que trata da prática profissional. Esta seção determina o desenvolvimento de projetos, onde através dos artigos de 292 a 297 estabelecem o escopo de atuação dos projetos, a supervisão, desenvolvimento, quantidade mínima por curso, orientação, finalidade, avaliação e a representatividade (OD-IFRN, 2012).

\section{PROJETO INTEGRADOR E ENSINO POR INVESTIGAÇÃO: CAMINHOS QUE SE CRUZAM}

Para a efetivação de um currículo integrado, é necessário que se proponham práticas integradoras. Moura (2007) sugere entre possíveis metodologias, para a concretização dos princípios da integração e da interdisciplinaridade, a implementação de projetos integradores que articulem os saberes vinculados pelas diversas disciplinas, bem como possibilitem uma associação com os problemas locais, regionais e profissionais.

Considerando essa preocupação, Henrique e Nascimento (2015) afirma que os projetos integradores são a materialização em componente curricular do exercício de práticas integradoras em instituições de ensino médio e superior do país. Algumas experiências integradoras vem sendo realizadas e revelam a potencialidade da utilização dessa prática pedagógica 
(BARRETO et al., 2007; ZEN e OLIVEIRA, 2013; ROCHA, SILVA e FONSECA, 2017; BRAGA e MONTEIRO, 2107).

O projeto integrador é um instrumento pedagógico que tem duração variável, podendo ser desenvolvido durante um bimestre, um semestre, ou até mesmo planejado para ser anual. Este por seu caráter integrador deve envolver mais de uma disciplina ou campo do saber, articulando teoria e prática, e podendo ser utilizado por diversas modalidades e níveis educacionais, tais como o Ensino Médio técnico Integrado, o Ensino Superior e o Ensino de Jovens e Adultos (EJA).

No Instituto Federal de Educação, Ciência e Tecnologia do Rio Grande do Norte (IFRN), o projeto integrador é um instrumento metodológico e avaliativo que envolve os diferentes níveis de ensino e tem o intuito de promover a flexibilização do currículo e a integração entre as diversas áreas do conhecimento (IFRN,2012).

O objetivo do projeto integrador é, portanto, permitir a articulação das disciplinas do eixo estruturante com as do eixo tecnológico, bem como, em uma visão interdisciplinar, buscar a solução de problemas que sejam relevantes para o curso em questão. Desta forma, o estudante é levado a perceber a importância de uma formação mais ampla e condizente com suas reais necessidades.

De acordo com o Projeto Político Pedagógico do Instituto Federal de Educação Tecnológica do Rio Grande do Norte, (IFRN-2012):

O projeto integrador apresenta-se como ferramenta desafiadora, sobretudo para o estudante. Por isso, deve partir da análise de uma problemática calcada em uma visão crítica; deve retratar uma trajetória de pesquisa; deve estimular a criatividade; deve promover a busca por novas descobertas; deve instigar a capacidade de observar e de interpretar as necessidades da sociedade, oportunizando intervenções nas práticas sociais; deve permitir adequação e correção de rumos nas ações planejadas, com base na identificação das necessidades de aprendizagens; e deve implicar a reflexão, da parte dos agentes envolvidos, acerca da gestão dos processos pedagógicos. (IFRN, 2012, p. 85).

No IFRN, Campus Pau dos Ferros, o projeto integrador constitui componente curricular obrigatório e formativo da prática profissional. Este consiste em uma disciplina específica que é coordenada por um professor do curso técnico (nas modalidades curso técnico integrado, EJA, ou Subsequente), em que o mesmo promove a integração entre os professores do eixo estruturante (propedêuticas) e do eixo tecnológico (específicas). Essa integração deve ser feita entre duas ou mais disciplinas. Formam-se grupos de alunos que devem ser orientados por um professor específico e definemse problemáticas que devem ser investigadas pelos grupos e levantadas hipóteses para a resolução do problema. O professor orientador normalmente 
se constitui das disciplinas específicas, mas pode também ser um professor das áreas propedêuticas.

Considerando os aspectos metodológicos do projeto integrador presentes no PPP, deve-se levar em consideração (IFRN, 2012, p.86):

a) o planejamento e a elaboração deve ser realizado em conjunto sempre considerando o perfil profissional do curso;

b) a temática deve ser pertinente à área de formação e as disciplinas envolvidas, bem como o trabalho deve ser acompanhado por um professor (do núcleo estruturante ou núcleo tecnológico);

c) a utilização da interdisciplinaridade, teoria e prática, e nas vivências profissionais;

d) a avaliação deve ser processual, valorizando os aspectos qualitativos.

O PPP ainda aponta as etapas que devem ser percorridas para a execução de um projeto integrador (IFRN, 2012, p.86-87): fase de intenção; preparação e planejamento; implementação; desenvolvimento e acompanhamento; e resultados finais.

A primeira fase, denominada de intenção, compreende a definição do problema a ser pesquisado, a justificativa para a execução do projeto, os objetivos que devem ser traçados pelo grupo, resultados esperados e abrangência do projeto.

A segunda fase é a de preparação e planejamento. Esta é a etapa que se planeja o desenho experimental do projeto (ou produto tecnológico), escolhe a metodologia e se projeta a apresentação dos resultados finais da pesquisa.

A fase operacional do projeto é a de implementação, desenvolvimento e acompanhamento, onde são realizados o levantamento dos dados coletados, apresentados resultados preliminares para apreciação do coletivo, as dificuldades encontradas e os resultados alcançados.

Por fim, tem-se a fase dos resultados finais que implica na sistematização dos resultados e avaliação dos objetivos pedagógicos, compreendendo a verbalização dos resultados por parte do estudante e apreciação da experiência vivida.

Embora o Ensino por Investigação seja uma abordagem didática aplicada ao ensino de ciências, suas premissas de exploração de questões, análise crítica, adoção da prática científica como princípio educativo, bem como o papel ativo do estudante e a mediação do docente, implica considerálo como uma abordagem condizente com as estratégias apontadas pelo projeto integrador. 
Para Trivelato e Tonidandel (2015), uma sequência investigativa de Biologia deve incentivar e propor aos alunos: uma questão problema que possibilite a reflexão e o desafio; a elaboração de hipóteses em pequenos grupos de discussão; a construção e registro de dados por meio de atividades práticas, experimentais ou de campo; a discussão dos dados com os seus pares e a redação científica sobre os processos e procedimentos; e a elaboração de afirmações e evidências colhidas a partir da investigação realizada.

Zompero e Laburú (2011) fazem uma análise das atividades de investigação no ensino de ciências, e chegam à conclusão de que algumas características devem estar presentes como: o engajamento dos alunos para a realização das atividades investigativas; a emissão de hipóteses; a busca de informações, seja por meio de experimentos, ou por buscas bibliográficas; a comunicação dos estudos feitos pelos alunos para os demais colegas na sala.

Neste aspecto, pode-se perceber que o modelo de projeto integrador se encaixa com uma abordagem investigativa, uma vez que é solicitada a autonomia dos estudantes para buscar soluções, bem como estabelecer planos de trabalho, coletar informações e analisar dados que são fornecidos ou pesquisados (Tabela 1).

Tabela 1: Comparação entre as etapas realizadas no Ensino de Ciências por Investigação e as etapas do Projeto Integrador

\begin{tabular}{c|c}
\hline $\begin{array}{c}\text { Etapas do ensino por } \\
\text { investigação* }\end{array}$ & Etapas do Projeto Integrador \\
\hline Problema & Intenção \\
\hline Hipóteses & Preparação e Planejamento \\
\hline Plano de trabalho & $\begin{array}{c}\text { Implementação, desenvolvimento e } \\
\text { acompanhamento }\end{array}$ \\
\hline Obtenção dos dados & Resultados finais \\
\hline Conclusão &
\end{tabular}

* Adaptado de Zompero e Laburú (2011)

Da mesma forma que a abordagem investigativa, a perspectiva dos projetos integradores capacita os alunos a adquirirem habilidades para a iniciação científica, bem como de comunicarem seus resultados na forma de relatórios de atividades e apresentação frente à comunidade escolar. $O$ projeto integrador apesar de buscar a autonomia e aprendizagem crítica, oferece ao professor o papel de orientador dos processos metodológicos, bem como permite uma aprendizagem direcionada e crítica dos estudantes.

Há, contudo, que se observar que o ensino por investigação é uma abordagem didática limitada às ciências da natureza que pretende investigar os fenômenos naturais. Os projetos integradores têm um campo de atuação 
bem mais amplo que pode ser explorado, englobando as ciências humanas e as linguagens, assim como os saberes técnicos e profissionais, sobretudo quando se considera o trabalho como princípio educativo, aliado à pesquisa como princípio pedagógico.

Ao assumir o trabalho como princípio educativo - mediação de primeira ordem entre o ser humano e o meio ambiente -, as estratégias pedagógicas adquirem ênfase no sentido de possibilitar a compreensão do processo social, cultural e histórico da ciência e tecnologia mediado pelo trabalho (RAMOS, 2011, p. 781).

A grande contribuição da abordagem investigativa recai na iniciação aos métodos, procedimentos e atitudes que a cultura científica desperta nos estudantes, bem como estimula a criatividade e a criticidade, características imprescindíveis para uma formação integral.

\section{CONCLUSÃO}

O ensino de ciências apresenta-se como uma abordagem das metodologias ativas dentro das ciências naturais, que permite ao estudante aprender ciências de uma forma dinâmica e dota o mesmo do chamado "espírito científico", ensinando-o a questionar as verdades concebidas, observar o mundo natural, formular hipóteses, testar teorias e comunicar resultados, adquirindo habilidades e valores éticos sobre a importância da pesquisa como princípio educativo.

Já os projetos integradores são estratégias metodológicas que estimulam a análise da realidade e a resolução de problemas, estimulando o estudante ao protagonismo estudantil e à iniciação científica, bem como à competência técnica para o exercício do trabalho na perspectiva integral.

Desse modo, os pressupostos básicos do Ensino por Investigação se alinham com o propósito dos projetos integradores, uma vez que estes estimulam o estudante a enveredar pelos caminhos da pesquisa científica e a resolver problemas inerentes ao seu campo de atuação profissional. Esse tipo de atividade situa a aprendizagem numa dimensão contextualizada, promovendo a articulação entre teoria e prática, bem como favorecendo a interação entre os conhecimentos gerais e os conhecimentos específicos.

A matriz curricular dos institutos é pensada de tal forma que permita ações integradoras, que não se limitem apenas à eventos esporádicos, como para atender exigências disciplinares, mas que deem margem para se expandir as possibilidades de integração.

Pensar em integração no âmbito da educação tecnológica é permitir o diálogo entre os saberes propedêuticos e tecnológicos, entre os diferentes níveis de educação, desde o ensino médio técnico, passando pelo superior, 
pelo Ensino de Jovens e Adultos (EJA) e pela modalidade de Ensino à Distância (EAD), assim como compartilhar esforços interdisciplinares para a resolução de problemas práticos que beneficiem a comunidade local.

Portanto, é importante ressaltar que uma abordagem investigativa não se restrinja apenas às ciências naturais, mas que haja a incorporação de saberes pertencentes ao campo da comunicação e das linguagens, bem como aspectos sócio-históricos para promover ações integradas entre as diversas disciplinas e buscar uma formação mais condizente com as atuais necessidades dos estudantes.

\section{REFERÊNCIAS}

1. AMORIM, A.C.R. O que foge do olhar das reformas curriculares: nas aulas de biologia, o professor como escritor das relações entre ciência, tecnologia e sociedade. Ciência \& Educação (Bauru), v. 7, n. 1, p. 4765, 2001.

2. ANDRADE, G.T.P Percursos históricos de ensinar ciências através de atividades investigativas. Ensaio Pesquisa em Educação em Ciências, v. 13, n. 1, 2011.

3. ARAUJO, R. M. D. L.; FRIGOTTO, G. Práticas pedagógicas e ensino integrado. Revista Educação em Questão, v. 52 , n. 38 , p. 61-80, 2015.

4. AZEVEDO, M.C.P.S. Ensino por investigação: problematizando as atividades em sala de aula. In: CARVALHO, A.M.P (Org.). Ensino de Ciências: unindo a pesquisa e a prática. Cengage Learning Editores, p.19-33, 2004.

5. BARRETO, A.B.P.C.M. et al. Uma experiência interdisciplinar: o Projeto Integrador na Licenciatura em Espanhol do CEFET/RN. HOLOS, v. 3, 2007.

6. BORGES, R.M.R., LIMA, V.M.R. Tendências contemporâneas do ensino de Biologia no Brasil. Revista electrónica de Enseñanza de las Ciências, v. 6, n. 1, p. 165-175, 2007.

7. Braga, A.H., Monteiro, E.A.M., Santos, M.M., Cunha, F.B. Projeto integrador: análise de uma experiência no IF goiano Campus Ceres. In: ARAÚJO, A.C.; SILVA, C.N.N. Ensino Médio Integrado no Brasil: Fundamentos, práticas e desafios. Brasília: IFB, 2017.

8. CAChapuZ, A., GIL-PÉREZ, D., CARVALHO, A.D., PRAIA, J., VILCHES, A (Orgs.). A necessária renovação do ensino das ciências. 3 ed. São Paulo: Cortez Editora,2011. 264p.

9. CARLETTO, M.R., PINHEIRO, N.A.M. Subsídios para uma prática pedagógica transformadora: contribuições do enfoque CTS. Investigações em Ensino de Ciências, v. 15, n. 3, p. 507-525, 2010.

10. CARVALHO, A.M.P (Org.). Ensino de Ciências-unindo a pesquisa e 
a prática. São Paulo: Pioneira Thomson Learning, 2004. 165p.

11.DELIZOICOV, D., ANGOTTI, J.A., PERNAMBUCO, M.M. Ensino de Ciências: fundamentos e métodos. Cortez Editora, 2011. 366p.

12.FAZENDA, I.C.A. Interdisciplinaridade: didática e prática de ensino. Interdisciplinaridade. Revista do Grupo de Estudos e Pesquisa em Interdisciplinaridade. n. 6, p. 9-17, 2015.

13. FRIGOTTO, G.; CIAVATTA, M.; RAMOS, M. (Orgs.). Ensino médio integrado: concepção e contradições. São Paulo: Cortez, 2005.

14.GOUW, A.M.S., MOTA, H.S., BIZZO, N. O currículo de Ciências e o interesse dos estudantes brasileiros: uma aproximação necessária. Cadernos Cenpec - Nova série, v. 3, n. 2, p.7-34, 2013.

15. IFRNa. Organização Didática do IFRN. Natal: IFRN, 2012. 82p.

16. IFRNb. Projeto Político-Pedagógico do IFRN: uma construção coletiva - DOCUMENTO- BASE. Natal-RN: IFRN, 2012. 326p.

17. IFRNc. Resolução no 38/2012, Conselho Superior - CONSUP/IFRN, de 26 de março de 2012.

18. HENRIQUE, A.L.S.; NASCIMENTO, J.M. Sobre práticas integradoras: um estudo de ações pedagógicas na educação básica. HOLOS, v. 4, 2015.

19. MARANDINO, M. A prática de ensino nas licenciaturas e a pesquisa em ensino de ciências: questões atuais. Caderno brasileiro de ensino de Física, v. 20, n. 2, p. 168-193, 2003.

20. MARTINS, A. F. P. Ensino de ciências: desafios à formação de professores. Revista Educação em Questão, v. 23, n. 9, p. 53-65, 2005.

21.MORÁN, J. Mudando a educação com metodologias ativas. Coleção Mídias Contemporâneas. Convergências Midiáticas, Educação e Cidadania: aproximações jovens, v. 2, p. 15-33, 2015.

22. MORIN, E. Os setes saberes necessários à educação do futuro. $2^{\underline{a}}$ ed.rev. São Paulo: Cortez; Brasília, DF: UNESCO, 2011. 102p.

23. MOURA, D.H. Educação Básica e Educação Profissional e Tecnológica: dualidade historica e perspectiva de integração. HOLOS, Natal, v.2, p.1-27, 2007.

24. MUNFORD, D., LIMA, M.E.C.C. Ensinar ciências por investigação: em quê estamos de acordo?. Ensaio Pesquisa em Educação em Ciências (Belo Horizonte), v. 9, n. 1, p. 89-111, 2007.

25. PACHECO, E. M. Os institutos federais: Uma revolução na Educação Profissional e Tecnológica. Natal: IFRN, 2010.

26. PAVÃO, A.C., FREITAS, D. (org.). Quanta ciência há no ensino de ciências. 1a ed. São Carlos: EdUFSCar, 2011. 322p.

27. RAMOS, M. N. O currículo para o Ensino Médio em suas diferentes modalidades: concepções, propostas e problemas. Educação \& 
Sociedade, v. 32, n. 116, p. 771-788, 2011.

28. RAMOS, M. N. Ensino Médio Integrado: da conceitualização à operacionalização. Cadernos de Pesquisa em Educação, v. 19, n. 39, p. 15-29, 2014.

29. ROCHA, A.; SILVA, M.L.R.N.; FONSECA, P.B.F. Projeto integrador do Campus avançado São João da Barra. In... Colóquio Nacional: A produção do conhecimento em Educação Profissional. 4. Natal: IFRN, 2017.p.1-12.

30.RODRIGUES, B.A., BORGES, A.T. O ensino de ciências por investigação: reconstrução histórica. Anais do XI Encontro de Pesquisa em Ensino de Física, p. 1-12, 2008.

31.SASSERON, L.H. Alfabetização científica, ensino por investigação e argumentação: relações entre ciências da natureza e escola. Ensaio Pesquisa em Educação em Ciências (Belo Horizonte), v. 17, n. spe, p. 49-67, 2015.

32. SASSERON, L.H., CARVALHO, A.M.P. Alfabetização científica: uma revisão bibliográfica. Investigações em ensino de ciências, v. 16, n. 1, p. 59-77, 2011.

33.SOBRAL, F.R., CAMPOS, C.J.G. Utilização de metodologia ativa no ensino e assistência de enfermagem na produção nacional: revisão integrativa. Revista da Escola de Enfermagem da USP, v. 46, n. 1, p. 208-218, 2012.

34.SOUZA, M.R., SILVA, M.L.T., SILVA, M.S. FORMAÇÃO INTEGRAL E INTEGRADA: UMA PERCEPÇÃO DOS DOCENTES DO CURSO DE INFORMÁTICA DO IFRN. Revista Brasileira da Educação Profissional e Tecnológica, v. 1, n. 12, p. 51-69, 2017.

35. TRIVELATO, S.L.F., TONIDANDEL, S.M.R. Ensino por investigação: eixos organizadores para sequências de ensino de biologia. Ensaio Pesquisa em Educação em Ciências, v. 17, p. 97-114, 2015.

36. VALDEZ, V. R. Desenvolvimento de uma matriz de competências e habilidades para repensar o ensino de ciências pela perspectiva do ensino por investigação. Dissertação, Universidade de Brasília, 2017. $164 p$.

37. VIEIRA, F.A. Ensino por investigação e aprendizagem crítica: análise fenomenológica do potencial de uma proposta de ensino. Tese (Doutorado). Universidade Estadual Paulista. Faculdade de Ciências, Bauru, 2012. 149p.

38.ZEN, E.T.; OLIVEIRA, E.C. O projeto integrador e a centralidade do trabalho para a formação humana no Programa de Integração da Educação Profissional com a Educação Básica na modalidade de Educação de Jovens e Adultos (PROEJA) IFES Campus Vitória/ES. In... Colóquio Nacional: A produção do conhecimento em Educação Profissional. 2. Natal: IFRN, 2013. p.1-10.

39.ZÔMPERO, A.F, LABURÚ, C.E. Atividades investigativas no ensino de 
ciências: aspectos históricos e diferentes abordagens. Ensaio Pesquisa em Educação em Ciências, v. 13, n. 3, p. 67-80, 2011. 